\title{
JUURNAL.RU
}

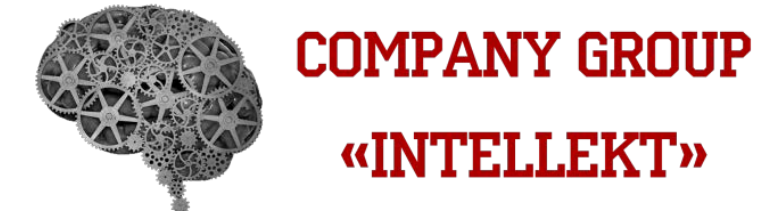

Ромейко К.А. Государственный Университет Управления Дзержинский, Россия

doi: 10.18411/lj2016-6-5-03

\section{Эффективность международной складской логистики}

Складская логистика представляет собой самостоятельную область знаний, имеет свой предмет и объект исследования, относится к ключевым логистическим активностям, а основной областью приложения ее усилий является сфера товародвижения; со склада начинаются и складом заканчиваются процессы товародвижения.

Для определения сущностной характеристики международной складской логистики инновационно-сервисного типа необходимо раскрыть ее цели, задачи, принципы и функции.

Целью складской логистики инновационно-сервисного типа является стремление к снижению совокупных затрат в процессе товародвижения на основе минимизации риска возможных потерь при реализации инновационносервисного потенциала логистической системы. Более всего на вероятность возникновения риска влияют следующие условия: неопределенность рыночной конъюнктуры, низкий уровень организации межфункциональных взаимосвязей и частота возникновения конфликтов.

В системе управления важно реализовать переход от вертикальной интеграции - к горизонтальной. Для того, чтобы складская логистика эффективно функционировала и достигала высоких результатов, она должна рассматриваться как составная часть всей логистической системы, связанная с другими ее составными звеньями общей целью и проблемами. Управление 
складской логистикой целесообразно осуществлять с использованием горизонтальных, интегрированных связей. В складской логистике должны быть сконцентрированы все внутренние резервы, что, в конечном счете, положительно скажется на снижении неценовых расходов и позволит свести воедино все требования, предъявляемые к складированию. Важно со стандартного подхода в складской логистике переключиться на инновационные методы решения проблем. К таким инновационным подходам в управлении складом можно отнести модели оптимального потребления ресурсов, инновационные модели управления запасами, аналитические методы ранжирования поставщиков, электронную коммерцию и др. Важную роль приобретает понимание характеристик, входящих в логистическую систему информационных потоков. Особое значение придается возможности оценки влияния полученной информации на развитие ситуации в системе поставок, понимать тенденции рынка поставок и экономическое положение поставщиков, видеть, как информационные потоки влияют на обеспечение выполнения заказа точно и к указанному сроку и полноту удовлетворения заказа; на надежность, точность и своевременность выполнения отгрузок, рационализацию запасов и др.

Вышеизложенные подходы можно рассматривать как принципы складской логистики инновационно-сервисного типа, что позволит дополнить ранее разработанные и апробированные методологические принципы логистики, основными из которых являются следующие: Принцип системного подхода применяется при характеристике элементов логистической системы как взаимосвязанных и взаимодействующих для достижения единой цели. Отличительной особенностью системного подхода в логистике является стремление к оптимизации функционирования всей логистической системы в целом, a не отдельных ее элементов. Принцип тотальных затрат, то есть принцип учета при проектировании логистических систем всей совокупности издержек на материальный поток и связанные с ним информационный, 
финансовый и сервисный потоки. При оптимизации логистических систем, как правило, выбирается критерий минимума общих логистических затрат. Принцип глобальной оптимизации - при оптимизации структуры логистической системы или совершенствовании методов управления для достижения общего оптимума необходимо согласование локальных целей функционирования всех элементов (звеньев) системы. Принцип логистической координации и интеграции. Для реализации поставленной цели необходимо достижение согласованного, интегрального участия всех элементов логистической системы. Принцип моделирования и информационно-компьютерной поддержки. Эффективная организация коммерческой логистики предполагает соответствующую информационно-компьютерную поддержку. Принцип всеобщего управления качеством - рассматривает надежность функционирования и высокое качество работы каждого элемента логистической системы как условие обеспечения общего качества товаров и их сервисного сопровождения. Принцип гуманизации всех функций и технологических решений в логистических системах предполагает их соответствие экологическим требованиям по охране окружающей среды, эргономическим, социальным и этическим требованиям работы персонала и т.п. Принцип устойчивости и адаптивности - способность логистической системы приспосабливаться к факторам внешней среды (изменение условий закупки и доставки материальных ресурсов, тарифной политики, колебаний спроса на продукцию и т.д.).

Функции складской логистики инновационно-сервисного типа можно рассмотреть с позиций интеграции процесса товародвижения, выделяя такие из них, как координирующая, оптимизирующая, интегрирующая, кооперирующая. Функции складирования отражают различные складские логистические процессы, включая также логистические операции. Проблема состоит в том, насколько эти функции адаптивны к складской логистики инновационносервисного типа. В этой связи стоит обратить внимание на то, что функции складской логистики инновационно-сервисного типа создают как 
экономические, так и сервисные выгоды. Экономические выгоды обеспечивает сокращение общих логистических издержек при внедрении инновационных схем управления экономическими потоками в системе товародвижения. Сервисные выгоды складирования реализуются за счет приближения запасов к рынку, формирования рыночного ассортимента, комплектования смешанных грузовых отправок, создания эффекта присутствия на рынке. При этом сервисные выгоды транспортно-складской логистики инновационно- сервисного типа могут не всегда сопровождаться снижением издержек. Сервисные выгоды складской логистики реализуются в том случае, если складирование способно реализовать полезность места и времени в системе поставок в целом.

Сегодня редко какой руководитель компании не задумывается о будущем бизнеса, о способах и возможностях увеличения объемов продаж, при этом вопросы логистики с каждой достигнутой целью начинают беспокоить его все чаще и чаще.

Неудивительно, ведь решение вопросов логистики в международных предприятиях всегда отходило на второй план, поскольку все логистические издержки традиционно компенсировались повышением маржи. В связи с обострения конкурентной борьбы, руководители компаний стали интересоваться уровнем затрат на логистику, в т.ч. оптимальности и эффективности работы складского хозяйства, причем как на уровне складов: снабжения, производства, вспомогательных материалов, так готовой продукции, распределительных центров готовой продукции, удаленных складов готовой продукции.

В ближайшие 2-3 года конкуренцию зарубежным цепям поставок составят четко структурированные и хорошо отлаженные логистические сети иностранных холдингов , что обеспечит им захват до 25\% доли рынка.

Продажи компании и повышение складских запасов - вот о чем думают руководители, когда планируют экспансию в 2-3 раза. При этом проблемы склада считаются надуманными, а весь происходящий структурный беспорядок 
- не иначе как «посредственным» отношением начальника склада и неумением его грамотно управлять складом.

Действительно, на складе могут существовать серьезные организационные проблемы, проблемы с ротацией персонала, технологией работы (внутренние проблемам склада), но большую роль в ситуации на складах играют смежные логистические процессы (закупки, продажи, транспорт). Поэтому прежде, чем начинать кардинальное изменение на складе требуется просчитать последствия все шагов оптимизации, в противном случае - последствия могут быть губительны, как для производства, так и системы продаж компании.

Обычно выделяют 5 последовательных шагов оптимизации склада:

1. провести логистический аудит склада;

2. провести реинжиниринг (проектирование) существующего склада;

3. изменить (разработать, автоматизировать) бизнес-процессы склада;

4. изменить (разработать) систему регламентов, мотивации и отчетности склада;

5. тиражировать систему управления складом / передать складскую логистику на аутсорсинг.

Профессиональное логистическое проектирование складского комплекса стоит не дешево и не многие компании сегодня готовы пойти на такие затраты (1-2\% от годового бюджета склада), однако, потери от ошибок при запуске склада (операционные затраты на этапе эксплуатации) обходятся компаниям еще дороже.

Самостоятельное проведение реинжиниринга (проектирования) складского комплекса требует определенных знаний и навыков, с другой стороны практические знания многих руководителей складов позволяют довольно точно описать требуемые параметры и предугадать решение многих складских проблем.

Таким образом, технология логистического проектирования склада носит циклический характер с числом итераций до 3-5 раз в зависимости от сложности 
участка, а общее количество вариантов планировочного решения достигает 1520. На основе опыта и технологий бережливой логистики отсеиваются лишние варианты и остаются только 2-3 альтернативных, наиболее удачных.

Основной особенностью логистического проектирования является ответы на максимальное количество вопросов по будущему складу, что дает понимание каким образом сэкономить не только на этапе строительства; позволяет существенно снижать операционные затраты при обслуживании склада, за счет:

- меньшего пробега техники внутри и вне склада;

- возможности обслуживания крупногабаритной и малотоннажной техники;

- возможности быстро получить/выписать складские документы;

- минимизировать время простоя в ожидании погрузки/разгрузки;

- быстрой разгрузки/отгрузки;

- быстрой приемки/размещении на хранение;

- быстрой комплектации.

а также получать дополнительную прибыль за счет:

о большего объема вместимости продукции на складе;

о возможности обслуживании как оптовых, так и мелко-оптовых клиентов;

о возможности вести автоматизированный учет грузов в реальном времени;

о возможности временно хранить груз клиента за плату.

Детальное проектирование логистики склада позволяет учесть все особенности конструкции и параметров земельного участка и внешней инфраструктуры склада и требования стратегии бизнес с другой стороны, в результате вырабатывая такой вариант застройки склада, этапы внедрения которого будут приносить клиенту дополнительную прибыль[3]. 
Наиболее эффективное сокращение затрат на хранение возможно за счет оптимального использования площади. Эффективное хранение товаров, оптимизация размещения товаров, консолидация неполных поддонов при размещении, хранение в мультиячейках, что включает зонирование по группам товаров и дает многие другие опции.

Постоянный анализ стоков и ежемесячные мероприятия по оптимизации способствуют в среднем пятипроцентной оптимизации пространства. В целом на разных этапах можо добиться от $5 \%$ до $20 \%$ экономии пространства складских территорий. Отметим, что без четких методик расчета оптимального запаса в магазине и на складе невозможно добиться достигнутого результата. Поэтому необходима совместная работа провайдера и клиента.

Первое средство повышения эффективности работы склада - это финансовая мотивация персонала в дополнительной выработке, из чего логично складывается универсализм сотрудников. Водитель погрузчика, завершив свой объем операций, может приступить к выполнению других операций, оплачиваемых дополнительно. Таким образом, рассчитывается оптимальное количество взаимозаменяемого персонала под проект. Сотрудники после завершения работы на своем участке заинтересованы в работе на другом участке. За счет этого удается эффективно управлять пиковыми нагрузками в складском комплексе. Помимо фиксации количественных показателей выработки, система предусматривает отслеживание качества произведенных операций и фиксирование ошибок, совершенных сотрудниками.

Для удобства сотрудников на складе целесообразно установить терминальные точки, которые позволяют работникам отслеживать индивидуальную выработку по смене online за прошедший период. При работе по данной системе сотрудник сам заинтересован в повышении своих показателей, так как от этого зависит его заработная плата.

В заключении отметим, что в настоящее время международный бизнес переживает хорошие времена, когда становится возможным эффективно 
заниматься бизнесом при помощи внедрения именно современных эффективных бизнес-технологий, в том числе в логистике снабжения, которые могут дать компании реальные преимущества перед конкурентами. 


\section{Литература:}

1. Внешнеторговая статистика в развитии международного маркетинга и логистики. Маркетинг. 2014. № 1 (134). С. 90-96.Воронов В.И., Воронов А.B., Ермаков А.A.

2. Введение в логистику А. А. Смехов. - М. : Транспорт, 2013. - 112 с.

3. Логистика и управление цепями поставок. Теория и практика. Основы логистики. Аникин Б.А.; Родкина Т.А.; Волочиенко В.А.; Заичкин Н.И.; Межевов А.Д.; Федоров Л.С.; Вайн В.М.; Воронов В.И.; Водянова В.В.; Гапонова М.А.; Ермаков И.А.; Ефимова В.В.; Кравченко М.В.; Серова С.Ю.; Серышев Р.В.; Филиппов Е.Е.; Пузанова И.А.; Учирова М.Ю.; Рудая И.Л. Учебное пособие / Москва, 2014.

4. Логистика: тренинг и практикум. Аникин Б.А., Вайн В.М., Водянова В.В., Воронов В.И., Гапонова М.А., Ермаков И.А., Ефимова В.В., Заичкин Н.И., Кравченко М.В., Пузанова И.А., Родкина Т.А., Серова С.Ю., Серышев Р.В., Федоров Л.С. Учебное пособие / Москва, 2014

5. Логистика: учебное пособие / Под ред. Б. А. Аникина, Т. А. Родкиной. М. : ТК Велби, 2010. - 408 с.

6. Логистика. Учебник. - М.: Проспект, 2010. - 398 Степанов В.И

7. Основные элементы эволюции элементов цепей поставок в международной логистике ЛОГИСТИКА. Проблемы и решения. Международный научно-практический Журнал. 2013 №, 2. Украина. Харьков. Воронов В.И., Воронов А.В

8. Рынок и логистика / Под ред. М. П. Гордона. - М. : Экономика, 2011. - 143 c.

9. Трансграничная логистика в Таможенном союзе России, Белоруссии и Казахстана [текст]: учебное пособие: Гриф УМО по образованию в области менеджмента для студентов высших учебных заведений, обучающихся по направлению «Менеджмент» - 080200 / Государственный 
университет управления, Институт управления на транспорте, в индустрии туризма и международного бизнеса ГУУ. - М. : ГУУ. 2013. -173 с. Лазарев В.А., Воронов В.И.

10. Управление потоками в логистических системах мировой экономики И. А. Еловой, В. И. Похабов, М. М. Колос ; под науч. ред. В. Ф. Медведева. Минск: Право и экономика, 2010. - 266 с.

11. Формирование управленческих решений логистики снабжения Карпова Н.П Вестн. Самар. гос. экон. ун-та. - 2010. - №11 (73). - С. 32-39. 